Sharif University of Technology
Scientia Iranica
SCIENTIA
I RAN I CA
http://scientiairanica.sharif.edu

\title{
The root causes of construction project failure
}

\author{
V. Shahhosseini ${ }^{a}, *$ M.R. Afshar ${ }^{a}$, and O. Amiri ${ }^{b}$ \\ a. Department of Civil and Environmental Engineering, Amirkabir University of Technology, Tehran, Iran. \\ b. Department of Civil Engineering, Islamic Azad University, Science and Research Branch, Tehran, Iran. \\ Received 21 October 2015; received in revised form 17 May 2016; accepted 26 September 2016
}

\author{
KEYWORDS \\ Construction project \\ failure; \\ Decision making; \\ Fault tree analysis; \\ Interval type-2 fuzzy \\ sets; \\ Uncertainty.
}

\begin{abstract}
Construction projects play an important role in the economic development of every country. Nevertheless, review of projects' documents indicates that, in most cases, the projects are not finished on assigned budget as scheduled, such that they sometimes loss their economic justification and simply fail. Consequently, devising suitable solutions is essential to the prevention of such failures. This is impossible without identifying the foremost causes of failure. In this study, first, all factors of failure are identified using Fault Tree Analysis (FTA). FTA as a diagnostic tool allows us to efficiently isolate root causes of failure. To rank these factors, dedicated specialists are requested to assess the risk of each cause using linguistic terms; thereby, relevant calculations are carried out using the Linguistic Weighted Average (LWA). Undeniably, considering the complexity of construction projects and incomplete expert knowledge, judgments must not be made using crisp value conception. Hence, fuzzy theory is utilized to achieve more accurate results. Results indicate that the majority of problems in projects stem from financial concerns and shortcomings of bidding process. In the last section, an actual case study is used to validate our results.
\end{abstract}

(C) 2018 Sharif University of Technology. All rights reserved.

\section{Introduction}

Construction projects play a significant role in the economic development of every nation. In most countries, construction projects absorb large sums of the capital asset investment from the state budget, and the construction industry in Iran is no exception [1]. According to Iran official statistics published in 2015, a total sum of 597 thousand billion Rials was invested exclusively in construction projects [2]. Though, regrettably, the majority of these projects failed to finish, and many others incurred cost and time overruns. Furthermore, the Research Center of the parliament of

\footnotetext{
*. Corresponding author. Tel.: +982164543058;

Fax: +982166414213

E-mail addresses: shahhosseini@aut.ac.ir ( $V$.

Shahhosseini); M.afshar67@aut.ac.ir (M.R. Afshar);

Omid121@aut.ac.ir (O.Amiri)
}

doi: $10.24200 /$ sci. 2017.4178 the Islamic Republic of Iran reported that no benefits gained from the current unfinished projects; this has not only damaged the national economy annually, but it has also cost the state over 200 thousand billion Rials (i.e., more than one-third of the country's annual development budget) [2]. Therefore, considering such outcomes, it is obvious that identifying, and subsequently, circumventing project failure in the construction industry is of utmost importance for the Iranian economy.

We should note that in this study, project failure is defined as follows:

1. Time and cost overrun such that the project losses economic justification, or;

2. The project is not completed.

In order to solve any special problem, the first step is to identify the main factors leading to that problem. This is only possible if effective tools are in place. The 
aim of this study is to emphasize the main causes of construction project failure using two different tools: 1) FTA and 2) LWA.

\section{Literature review}

In the literature, many researchers have recognized the main causes of project failure by applying different approaches. We address some of the recently published ones.

Han et al. [3] assessed challenges, obstacles, and performances of the Korea Train eXpress (KTX) project. First, critical sections in the railway route that incurred considerable delays to project completion were recognized. After that, the causes of these critical sections were examined carefully. Analysis revealed five major delay causes for the KTX project: lack of owner's abilities and strategies to manage hi-tech-oriented mega projects; frequent changes of routes caused by the struggles between public agencies and growing public opposition derived from environmental concerns; an unsuitable project delivery system; lack of suitable scheduling tools customized for a linear mega project; redesigning and changing orders of the main structures and tunnels for high-speed railways, which is essentially unlike traditional railway structures. AbdulRahman et al. [4] addressed the matters pertaining to financial-related delays in construction projects. They recognized the core causes and studied the appropriate alleviation actions required to remedy financial-related project delays. Primary data were composed by means of an initial interview, questionnaire survey, and indepth structured interviews. A total of 110 responses were acquired from a group of clients, contractors, consultants, and bankers. Results exposed poor cash flow management as the most important factor that leads to a project's delay followed by late payments, inadequate financial resources, and volatility in financial markets. Yang and Wei [5] found 35 delay factors. Fifteen factors were related to the planning phase, and 20 others were related to the design phase. Using the importancefrequency matrix, they concluded that the change in owner's project requirements is the predominant cause of project delay. Soliman [6] recognized 29 causes of delay in construction projects in Kuwait, and then characterized them in six groups. The causes were graded based on the Relative Importance Index (RII). He demonstrated that financial and design problems are the main factors behind delay. Hasseb et al. [7] scrutinized the dynamics behind delay of construction projects in Pakistan. First, they identified 37 delay factors. To rank these factors, they distributed 200 questionnaires among construction firms and inquired about the importance of each factor. Lastly, the factors were weighed by critical assessment criteria. The results indicate that client factors are the key sources of delay. Doli et al. [8] explored the delay causes of construction projects in India. Using a selected set of 45 attributes, this study identified the key factors affecting delay in the Indian construction industry, and then established the relationship between the critical attributes to develop prediction models for measuring the impacts of these factors on delay. A questionnaire and personal interviews formed the foundation of this research. Factor analysis and regression modelling were employed to study the implications of the delay factors. From the factor analysis, the major critical factors of construction delay were identified as (1) lack of commitment; (2) inefficient site management; (3) poor site coordination; (4) improper planning; (5) lack of clarity in project scope; (6) lack of communication; and (7) substandard contracts. The regression model specified that owner's slow decisionmaking process, poor labor productivity, architects' reluctance for change and rework due to mistakes in construction are the reasons which significantly affect the overall delay of the project. Ezeldin and AbdelGhany [9] found the main reasons of delay through interview with stakeholders; thereafter, for each reason, they determined one party responsible. The latter was conducted using a modified questionnaire. Based on their results, the leading five categories led to the causes of delay: 1) construction; 2) managerial; 3) political; 4) financial; and 5) technical factors. Rahsid et al. [10] identified the causes of delay using structured questionnaires distributed among construction firms. To find the main causes, they used several statistical instruments including reliability test, factor analysis, and regression. Their conclusions indicate that the existing problems correspond to contractor, client, consultant, material, and equipment factors. Marzouk and El-Rasas [11] analyzed causes of delay in Egyptian construction projects. They offered a list of construction delay causes retrieved from the literature. The feedback of construction experts was acquired through interviews. Next, a questionnaire survey was prepared and distributed between thirtythree construction experts who represent owners, consultants, and contractor organizations. Frequency Index, Severity Index, and Importance Index were calculated, and according to the highest values, the top ten causes of delay in construction projects in Egypt were determined. Similarly, a case study was analyzed and compared to the most important delay causes in their research. Statistical analysis was conducted using analysis of variance ANOVA to test delay causes obtained from the survey. Ruqaishi and Bashir [12] explored the factors behind failure in the oil and gas industry in Oman. They circulated 59 questionnaires among project managers to find the major causes of project delay. They concluded that poor interaction with vendors is the central cause of delay. 
Remon and Abdel-Hakam [13] studied the causes of delay in road construction projects in Egypt. They distributed 500 questionnaires among construction companies. They employed RII in order to rank the delay factors, and the top twenty factors were recognized. A real case study was used to confirm the results.

As can be observed, all the mentioned studies investigated the causes of delay through crisp value conceptions. However, due to the complexity of construction projects and deficiencies of expert knowledge, using crisp values cannot be correct. In this condition, fuzzy theory aids us to acquire more accurate results. In this course, Gunduz et al. [14] explored the key dynamics of failure using the Fuzzy Type-1 (FT1) approach. They initially found 83 delay factors and classified them into nine groups through a field study. Then, the experts were requested to provide an answer for the importance of each factor. Lastly, the related calculation was conducted by Fuzzy Type1 Sets (FT1Ss).

Yet, in group decision making, due to the lack of agreement on linguistic terms among experts, Fuzzy Type-2 (FT2) performs better than its predecessor. Thus, in this paper, we employed the FT2 approach.

\section{Methodology}

In order to ascertain the key causes of project failure, the proposed framework is presented in Figure 1 including three main steps:

- Step 1. Identification of basic events. In this paper, FTA is proposed to identify the root causes of failure. This analysis is carried out via interview with experts and reviews of literature. FTA as a diagnostic tool enables us to find the main causes of different problems more efficiently using hierarchical analysis. Additionally, understanding a problem is easy since the results of FTA are demonstrated in graphical form within a fault tree diagram. The fault tree diagram is a graphical model of various parallel and sequential arrangements of faults that can result in incidence of undesired events. The faults may comprise human errors, software errors, or any other errors, which can lead to undesired events [15]. In fault tree diagram, the undesired event is called top event, and the immediate causes of top events are called gate events. The analysis of a fault tree diagram should be continued to reach primary events, namely basic events. The basic events are not further developed, and by using logical gates (AND or OR gates), the basic events are connected to the top event [16]. When the "AND gate" is utilized, the upper event cannot follow unless all of its lower events occur. The "OR gate" specifies that the incidence of any of lower events is sufficient for the upper event to occur. The gates and their representative shapes are presented in Table 1 [16].

Using the existing literature and interview with experts, the fault tree diagram for construction projects is drawn (see Figure 2). As can be seen, the factors of failure have been categorized in four groups:

(a) Contractor-related factors;

(b) Client-related factors;

(c) Consultant-related factors;

(d) External factors.

Then, in each group, three phases of a project have been independently surveyed through FTA.

In Figure 2, contractor, client, consultant, and external factors are gate events, and regarding the gate events, 75 basic events have been found. These rudimentary events are the core factors behind construction project failure.

- Step 2. Evaluation of basic events. In this step, the experts were requested to assess the risk of each basic event through linguistic terms defined in nine

Table 1. The related shapes for "AND gate" and "OR gate" in fault tree diagram.

AND gate
OR gate

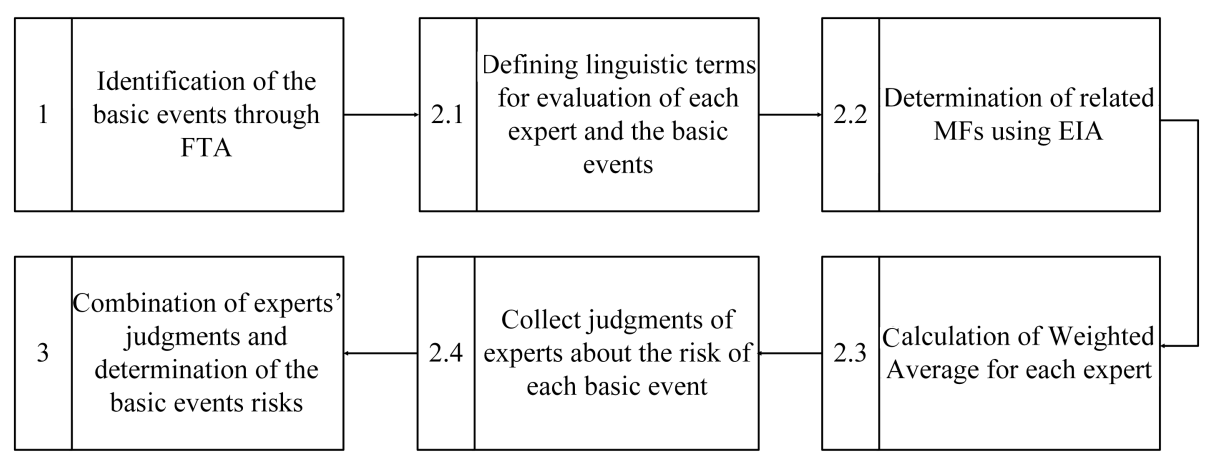

Figure 1. The proposed framework for finding the key causes of project failure. 


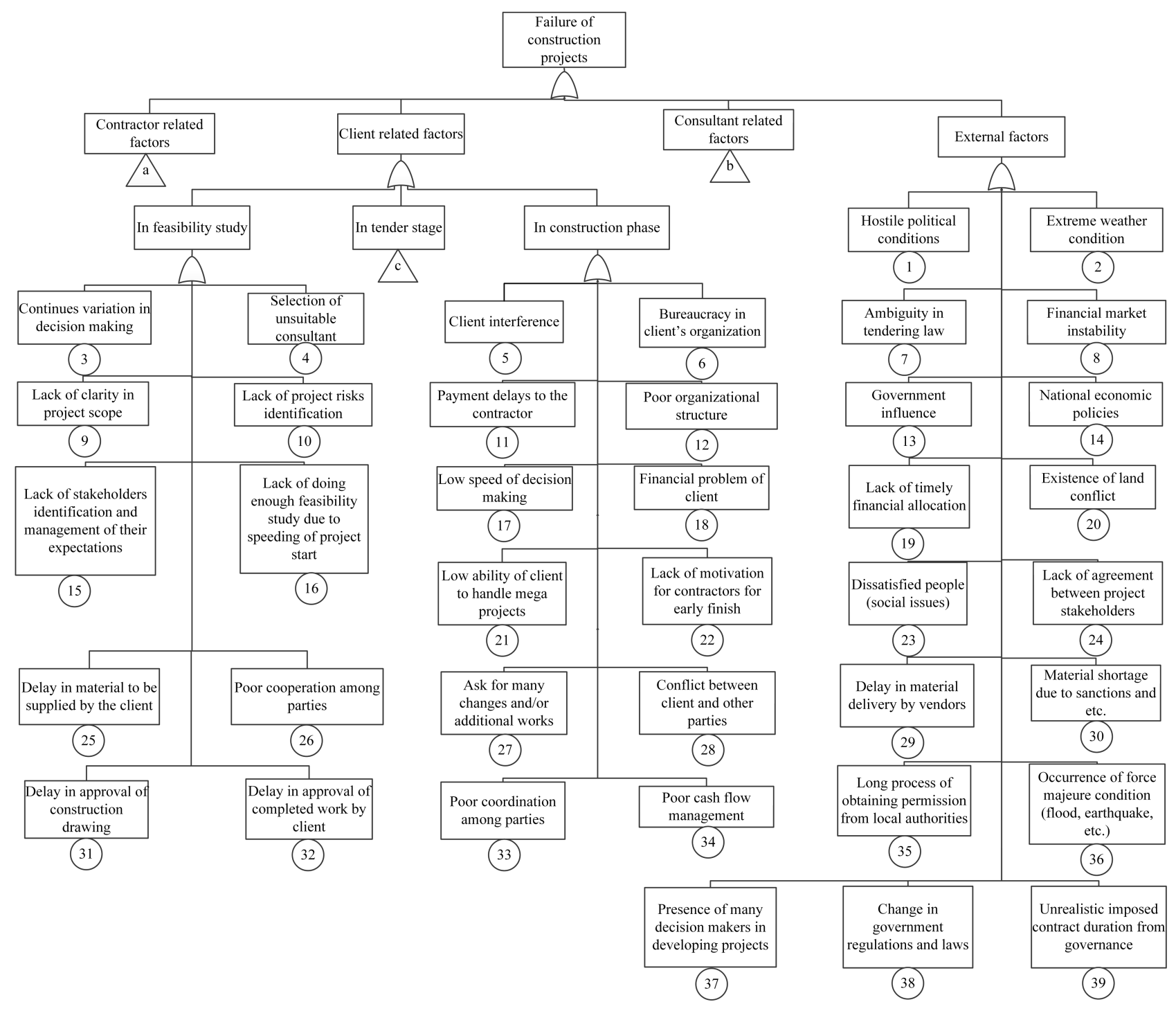

Figure 2. Fault tree diagram for construction project failure.

levels: \{Extremely Low, Very Low, Slightly Low, Low, Medium, Slightly High, High, Very High, and Extremely High $\}$. It has been proven in psychology that the number of objects an average human can hold in working memory is $7 \pm 2$. For this reason, nine levels of linguistic terms were selected [17].

Since the experts are not at the same level, their weight must be considered in risk evaluation. We recognize that an expert is described based on two qualities: 1) expertise, and 2) experience. Therefore, three criteria are considered: 1) educational level; 2) profession; and 3) service time (see Table 2). Based on a number of interviews, seven linguistic terms are defined to assess each expert in each one of the criteria: \{Inferior, Very Poor, Poor, Fair, Good, Very Good, and Superior $\}$. Hence, three linguistic terms are assigned to each expert. Then, the final weight of each expert is processed through Weighted Average (WA) of linguistic terms (Eq. (1)) allocated to each expert:

$$
\tilde{W}_{j}=\frac{w_{j}^{1} \oplus w_{j}^{2} \oplus w_{j}^{3}}{3},
$$

where $\tilde{W}_{j}$ is the WA of expert $j$, and $W_{j}^{q}$ is the linguistic term assigned to each expert $j$ in criterion $q(q=\{1,2,3\})$.

Since the population size of this research is very large, a subset of them using the sampling method is selected for economic reasons. Sampling is basically concerned with the selection of an appropriate subset of the whole population, which statically represents its characteristics. Human resources in construction companies of Iran comprise the population under study; accordingly, clustering sampling technique is employed for sampling, because it is best suited when there are homogeneous groupings. In this technique, clusters are selected randomly, and we need to 


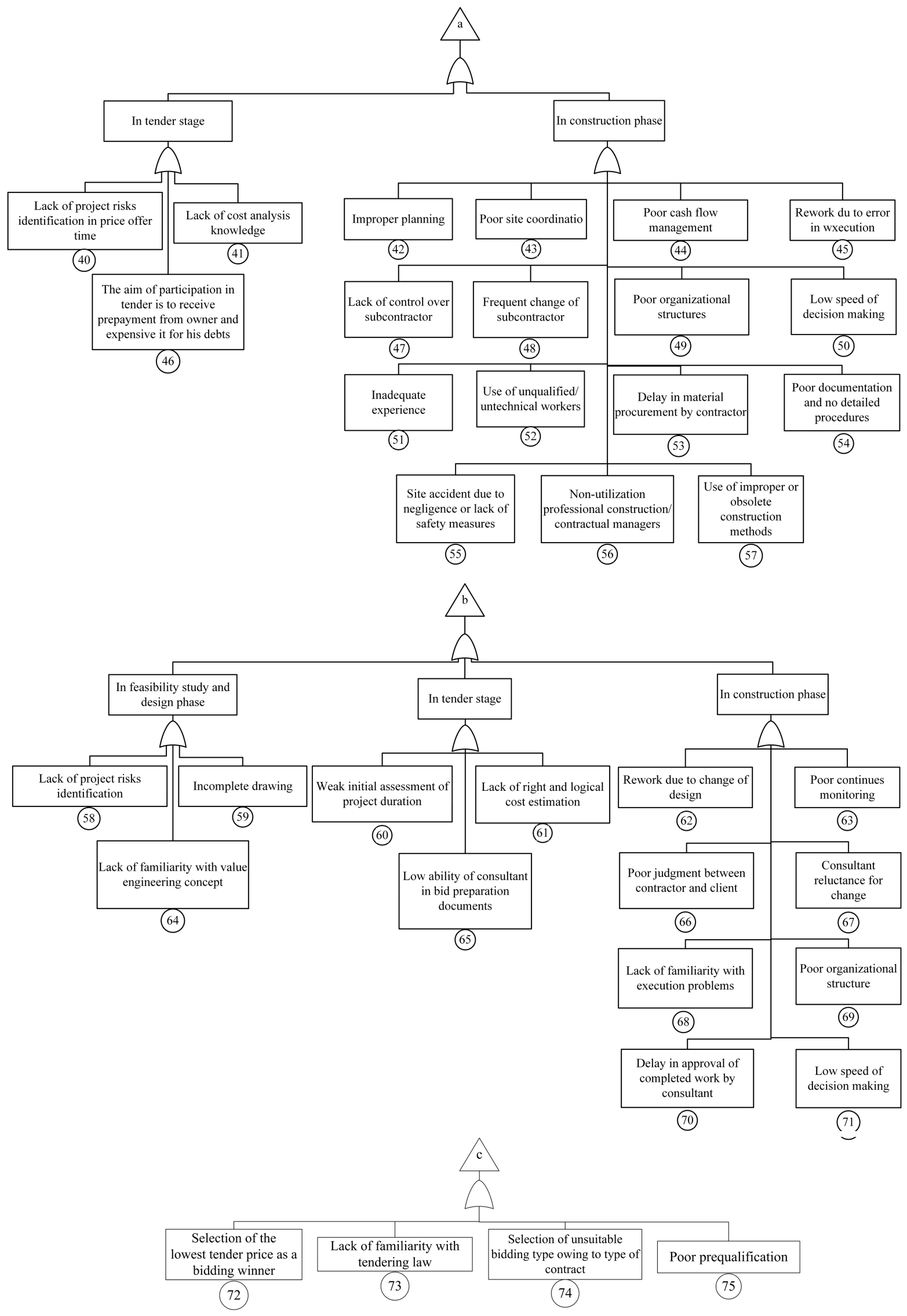

Figure 2. Fault tree diagram for construction project failure (continued). 
Table 2. Linguistic terms for different experts.

\begin{tabular}{|c|c|c|c|}
\hline Constitution & Classification & & Linguistic terms \\
\hline \multirow{7}{*}{ Educational level } & $\mathrm{PhD}$ & Professor & Superior \\
\hline & & Assistant Professor & Very Good \\
\hline & & Associated Professor & Good \\
\hline & MSc & & Fair \\
\hline & $\mathrm{BSc}$ & & Poor \\
\hline & Junior college level & & Very Poor \\
\hline & School level & & Inferior \\
\hline \multirow{7}{*}{ Profession } & Project Manager & With more than ten times experience & Superior \\
\hline & & With between five times and nine times experience & Very Good \\
\hline & & With between two times and four times experience & Good \\
\hline & & With one time experience & Fair \\
\hline & Engineer & & Poor \\
\hline & Technician & & Very Poor \\
\hline & Laborer & & Inferior \\
\hline \multirow{7}{*}{ Service time } & $>30$ years & & Superior \\
\hline & $25-30$ & & Very Good \\
\hline & $20-25$ & & Good \\
\hline & $15-20$ & & Fair \\
\hline & $10-15$ & & Poor \\
\hline & $5-10$ & & Very Poor \\
\hline & $<5$ & & Inferior \\
\hline
\end{tabular}

apply it for selecting construction companies. Then, experts within responsive companies are surveyed. In addition to the ease of implementation, this technique is more economical. The correct combination and estimation of sample size have a pivotal role in minimizing sampling bias. There are different ways to calculate appropriate sample size. These include using a census for small populations, imitating a sample size of similar studies, using published tables, and applying formulas to calculate a sample size. In this study, the sample size is estimated by the formula developed by Cochran [18] (Eq. (2)):

$$
n=\frac{N Z_{\alpha / 2}^{2} P(1-P)}{\varepsilon^{2}(N-1)+Z_{\alpha / 2}^{2} P(1-P)},
$$

where $n$ is the sample size, $N$ is the size of population, $P$ is the estimated proportion of an attribute that is present in the population, $Z$ is a standard normal quantile, $\alpha$ is the confidence level, and finally $\varepsilon$ is the level of precision.

The first stage of clustering involves choosing a subset of the first-rate construction companies according to strategic planning and monitoring section of government. Size of the population $(N)$ in this stage is 235 . The companies holding the first rank in the fields of construction, roads, and transportation and water transmission are desired (23 companies).
As a result, the desired proportion of attribute $(P)$ equals 23/235. The confidence level is considered $95 \%$. The level of precision is equal to $10 \%$. The value of $Z$ according to $95 \%$ confidence level is equal to 1.96. Finally, the sample size $(n)$ based on Cochran formula is estimated to be 8 . It is worth mentioning that the result indicates the minimum required number of responses. To achieve at least 8 responses, more than 20 inquiries were made, but only 10 inquiries were answered, which is the sample size of this study.

- Step 3. Combination of experts' judgments. The judgments made by different experts need to be combined into a single judgement in order to obtain the risk of each basic event. LWA is used for this purpose (Eq. (3)):

$$
\tilde{R}_{i}=\frac{\sum_{j=1}^{10} \tilde{W}_{j} \times \tilde{X}_{i j}}{\sum_{j=1}^{10} \tilde{W}_{j}},
$$

in which $\tilde{R}_{i}$ is the overall risk of basic event $i, \tilde{W}_{j}$ is the WA of expert $j$, and $\tilde{X}_{i j}$ is the response of expert $j$ to the risk of basic event $i$.

Nonetheless, we cannot use Eqs. (1) and (3) until the inputs are the linguistic terms. Therefore, 


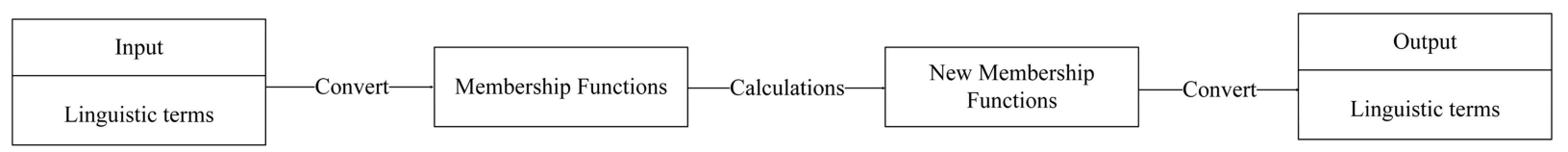

Figure 3. Fuzzy engine.

the fuzzy engine is utilized for this purpose. As can be seen in Figure 3, the linguistic terms are initially converted to fuzzy sets. Then, the associated calculations are carried out; lastly, the output fuzzy sets are once again transformed into linguistic terms. Using these outputs, we can decide reliability.

\section{Interval type-2 fuzzy sets}

Considering the complexity of construction projects and extensive interaction of events, using precise numerical evaluations is inconsistent [19] and evaluations are conducted based on linguistic terms, although a natural language is imprecise, uncertain, and partially true [20]. To evaluate basic events, it is crucial to convert linguistic terms into mathematical concepts. T2FSs are selected for this purpose. With this selection, the ambiguity inherent in a natural language is minimized [21]. In the literature, FT1 is commonly suggested to answer these problems. Yet, linguistic words of experts are very unclear, and thus, it is very hard to handle and estimate them using T1FSs, because type 1 representation is a reductionist approach and its Membership Functions (MFs) are totally crisp rather than fuzzy [21]. Furthermore, Mendel [22] established that employing T1FSs to model linguistic words is scientifically inappropriate. T2FSs have elucidated this problem by offering us more degrees of freedom for handling uncertainties. T2FSs are 'fuzzy fuzzy' sets (i.e., they are T1FSs whose grades of membership are also T1FSs). As the computational complexity of general T2FSs is severe, the Interval Type-2 Fuzzy Set (IT2FS) is used, which is a special case of generalized T2F. In [17], Wu and Mendel offered a technique using the LWA and IT2FSs by which the views of experts are aggregated. In this paper, Wu and Mendel's [17] approach is used to rank the core factors of construction project failure.

This section offers the definition of the mathematics behind IT2FSs, including calculation of fuzzy sets by means of $\alpha$-cuts and WA. Fundamentally, T2FSs are fuzzy sets that exhibit uncertainty in their MFs. These types of sets are convenient in conditions where defining a precise fitness function is hard or impossible. The mathematical definitions of the T1FSs and T2FSs and their arithmetic are as follows.

Definition 1. A T1FS $\tilde{A}$ in a universe of discourse, $X$, is characterized by Membership Function (MF)
$\mu_{\tilde{A}}(x)$. This MF denotes the membership value of member $x$ in set $\tilde{A}$ and takes values in the interval $[0,1][23]$.

Definition 2. $\alpha$-cut of a T1FS $\tilde{A}$ is a crisp set that contains all the elements in $X$ whose membership values are greater than or equal to $\alpha$, i.e.:

$$
A(\alpha)=\left\{x \mid \mu_{A}(x)>\alpha\right\}, \quad \forall X \in X, 0 \leq \alpha \leq 1 .
$$

In order to calculate the addition, subtraction, multiplication, and division of a type 1 fuzzy number, it is necessary to obtain $\alpha$-cut of fuzzy numbers. Then, calculations are implemented as in Definition 3 [23].

Definition 3. Suppose that $[a, b]$ and $[d, e]$ are $\alpha$-cut of FT1Ss $\tilde{A}_{1}$ and $\tilde{A}_{2}$, respectively (for $0 \leq \alpha \leq 1$ ), and multiplication and division of $\alpha$-cut of fuzzy sets $\tilde{A}_{1}$ and $\tilde{A}_{2}$ will be defined as follows [24]:

$$
\begin{gathered}
\tilde{A}_{1} \oplus \tilde{A}_{2}=[a, b]+[d, e]=[a+d, b+e], \\
\tilde{A}_{1}-\tilde{A}_{2}=[a, b]-[d, e]=[\min (a-d, b-e), \\
\max (a-d, b-e)] \\
\tilde{A}_{1} \otimes \tilde{A}_{2}=[a, b] \cdot[d, e]=[\min (a d, a e, b d, b e), \\
\max (a d, a e, b d, b e)] \\
\tilde{A}_{1} / \tilde{A}_{2}=[a, b] /[d, e]=[\min (a / d, a / e, b / d, b / e), \\
\max (a / d, a / e, b / d, b / e)] .
\end{gathered}
$$

Definition 4. Eq. (6) is one of the defuzzification methods for T1FSs and is used to find the centroid of a T1FS [24]:

$$
c(A)=\frac{\sum_{i=1}^{N} x_{i} \mu_{A}(x)}{\sum_{i=1}^{N} \mu_{A}(x)} .
$$

Definition 5. A general type-2 fuzzy set $\tilde{\tilde{A}}$ in the universe of discourse $X$ can be presented by type- 2 MFs $\mu_{\tilde{\tilde{A}}}$, shown as follows [24]: 


$$
\begin{aligned}
\tilde{\tilde{A}}= & \left\{\left((x, u), \mu_{\tilde{\tilde{A}}}(x, u)\right) \mid \forall x \in X, \forall u \in J_{x} \subseteq[0,1],\right. \\
& \left.0 \leq \mu_{\tilde{\tilde{A}}}(x, u) \leq 1\right\}
\end{aligned}
$$

where $x$ is a primary variable, $J_{x}$ is a primary MF, $u$ is a secondary variable, and $\mu_{\tilde{A}}(x, u)$ is a secondary MF [24]. follows:

Another representation form of a T2FS is as

$$
\tilde{\tilde{A}}=\int_{x \in X} \int_{u \in J_{x}} \frac{\mu_{\tilde{A}}(x, u)}{(x, u)},
$$

where $J_{x} \subseteq[0,1]$ and $\iint$ denote the union over all permissible $x$ and $u$.

Definition 6. When $\mu_{\tilde{A}}(x, u)=1, \forall \mu \in J_{x} \subseteq[0,1]$, we have an IT2FS, shown as follows:

$$
\tilde{\tilde{A}}(x, u)=\int_{x \in X} \int_{u \in J_{x}} \frac{1}{(x, u)} .
$$

Although the third dimension of IT2FSs, which is the value of the secondary MF, always equals one (i.e., the third dimension is ignored), it is still powerful enough to accurately cover uncertainty of words [24].

As can be seen in Figure 4, the union of all the primary memberships of an IT2FS is represented by a two-dimensional domain, which is called the Footprint Of Uncertainty (FOU) of $\tilde{\tilde{A}}$ :

$$
\begin{aligned}
& \operatorname{FOU}(\tilde{\tilde{A}})=\bigcup_{x \in X} J_{x}, \\
& \tilde{\tilde{A}}=\frac{1}{\operatorname{FOU}(\tilde{\tilde{A}})} .
\end{aligned}
$$

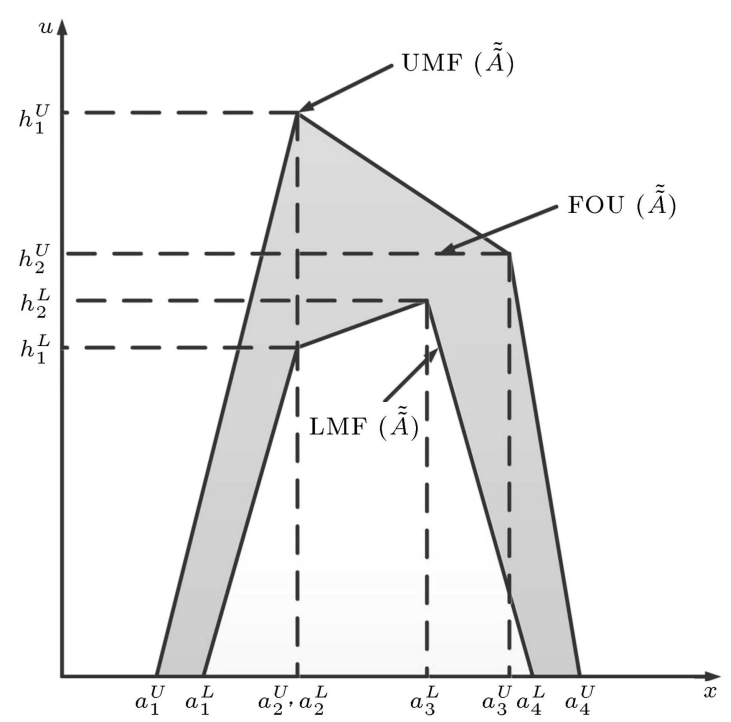

Figure 4. FOU, LMF, and UMF of a T2FS [24].
In other words, the FOU is completely described by its two bounding functions. The upper bound is called Upper Membership Function (UMF), denoted as $\bar{\mu}_{\tilde{A}}(x)$, and the lower bound is called Lower Membership Function (LMF), denoted as $\underline{\mu} \tilde{\tilde{A}}(x)$, i.e.:

$$
\begin{aligned}
& \bar{\mu}_{\tilde{\tilde{A}}}(x)=\overline{\operatorname{FOU}(\tilde{\tilde{A}}),} \\
& \underline{\mu} \tilde{\tilde{A}}(x)=\underline{\operatorname{FOU}(\tilde{\tilde{A}})} .
\end{aligned}
$$

In the following, some of the arithmetic operations between IT2FSs are presented. To start, suppose that $\tilde{\tilde{A}}_{1}$ and $\tilde{\tilde{A}}_{2}$ are two IT2FSs:

$$
\begin{aligned}
\tilde{\tilde{A}}_{1}= & \left(\tilde{\tilde{A}}_{1}^{U}, \tilde{\tilde{A}}_{1}^{L}\right)=\left(\left(a_{11}^{U}, a_{12}^{U}, a_{13}^{U}, a_{14}^{U} ; h_{11}^{U}, h_{12}^{U}\right),\right. \\
& \left.\left(a_{11}^{L}, a_{12}^{L}, a_{13}^{L}, a_{14}^{L} ; h_{11}^{L}, h_{12}^{L}\right)\right), \\
\tilde{\tilde{A}}_{2}= & \left(\tilde{\tilde{A}}_{2}^{U}, \tilde{\tilde{A}}_{2}^{L}\right)=\left(\left(a_{21}^{U}, a_{22}^{U}, a_{23}^{U}, a_{24}^{U} ; h_{21}^{U}, h_{22}^{U}\right),\right. \\
& \left.\left(a_{21}^{L}, a_{22}^{L}, a_{23}^{L}, a_{24}^{L} ; h_{21}^{L}, h_{22}^{L}\right)\right) .
\end{aligned}
$$

Definition 7. In IT2Fs, the aforesaid calculations for T1FSs in Definition 3 are separately carried out for its upper and lower bounds, and the result of addition, subtraction, multiplication, or division is found. For example, the addition operation between the IT2FSs above is defined as follows [17]:

$$
\begin{aligned}
\tilde{\tilde{A}}_{1} \oplus \tilde{\tilde{A}}_{2}= & \left(\left(a_{11}^{U}+a_{21}^{U}, a_{12}^{U}+a_{22}^{U}, a_{13}^{U}+a_{23}^{U}, a_{14}^{U}\right.\right. \\
& +a_{24}^{U} ; \min \left(h_{11}^{U}, h_{21}^{U}\right), \min \left(h_{12}^{U}, h_{22}^{U}\right) \\
& \left(a_{11}^{L}+a_{21}^{L}, a_{12}^{L}+a_{22}^{L}, a_{13}^{L}+a_{23}^{L}, a_{14}^{L}+a_{24}^{L} ;\right. \\
& \left.\min \left(h_{11}^{L}, h_{21}^{L}\right), \min \left(h_{12}^{L}, h_{22}^{L}\right)\right) .
\end{aligned}
$$

Definition 8. Crisp value, $\lambda$, is multiplied by an IT2FS as in the following equation [17]:

$$
\begin{aligned}
\lambda \tilde{\tilde{A}}_{1}= & \left(\left(\lambda a_{11}^{U}, \lambda a_{12}^{U}, \lambda a_{13}^{U}, \lambda a_{14}^{U} ; h_{11}^{U}, h_{12}^{U}\right),\right. \\
& \left.\left(\lambda a_{11}^{L}, \lambda a_{12}^{L}, \lambda a_{13}^{L}, \lambda a_{14}^{L} ; h_{11}^{L}, h_{12}^{L}\right)\right) .
\end{aligned}
$$

Definition 9. To obtain the centroid of IT2FS $\tilde{\tilde{A}}$, the average centroid between the centroids of UMF and LMF can be used [17]:

$$
c(\tilde{A})=\frac{c(U M F(\tilde{A}))+c(L M F(\tilde{A}))}{2} .
$$

\subsection{MFs definition}

For the purpose of determining the MFs of linguistic 
terms defined in Step 2, the experts were initially requested to say interval endpoints of each linguistic term. Then, the Enhanced Interval Approach (EIA) [19] was utilized to find all MFs. EIA determines MFs by means of the mean and variance of the interval endpoints. The obtained MFs are presented in Figures 5 and 6 . Similarly, their FOUs are presented in Tables 3 and 4.
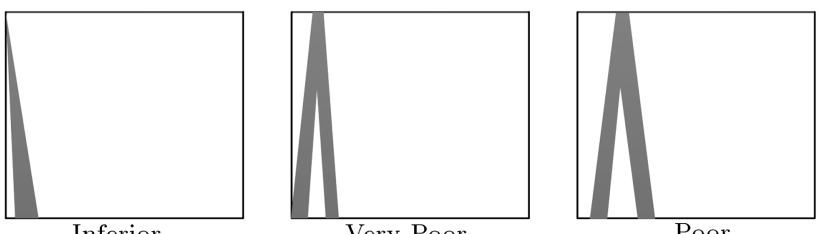

Inferior Very Poor
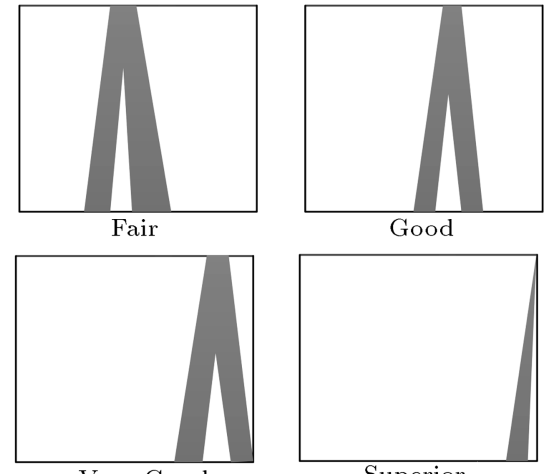

Very Good

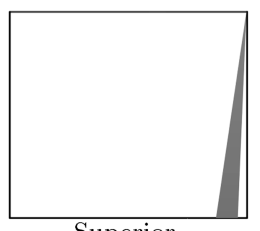

Superior

Figure 5. MFS of the linguistic terms for the evaluation of each expert.
Ten experts that had been nominated as a suitable subset of the whole statistical population of this research have been assessed, as shown in Table 5; their Weighted Averages (WAs) are reflected in Table 6 using Eq. (1) and Definitions 7 and 8. Correspondingly, the MFs associated with the WAs of Experts 1, 3, and 10 are shown in Figure 7 . For example, the output

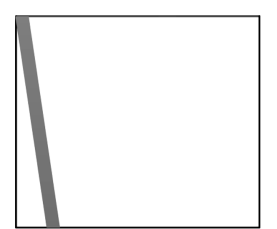

Extremely Low

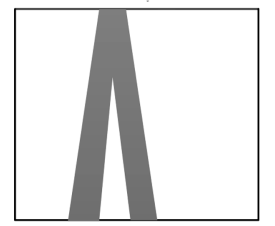

Slightly Low

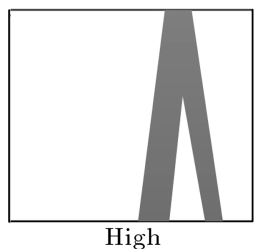

High

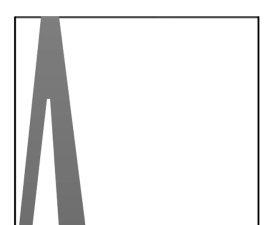

Very Low

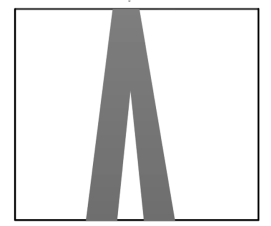

Medium

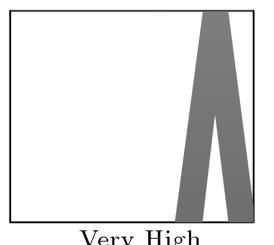

Very High
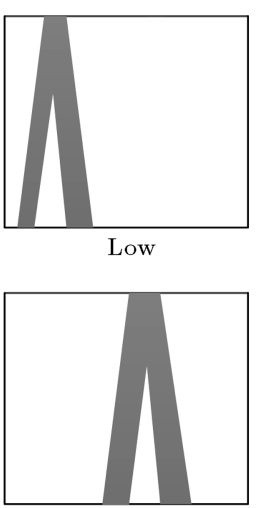

Slightly High

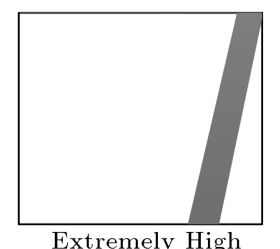

Extremely High
Figure 6. MFS of the linguistic terms for the evaluation of each basic event.

Table 3. Linguistic terms and their corresponding FOUs for the evaluation of each expert.

\begin{tabular}{ll}
\hline Linguistic terms & \multicolumn{1}{c}{ FOUs } \\
\hline Superior & $\mathrm{EL}=((0.00,0.00,0.14,1.97 ; 1,1),(0.00,0.00,0.05,0.66 ; 1,1))$ \\
Very Good & $\mathrm{VL}=((0.00,1.00,1.50,2.31 ; 1,1),(0.80,1.25,1.25,1.71 ; 0.64,0.64))$ \\
Good & $\mathrm{L}=((0.83,2.25,3.25,4.66 ; 1,1),(1.84,2.75,2.75,3.66 ; 0.64,0.64))$ \\
Fair & $\mathrm{M}=((2.89,4.05,5.30,6.71 ; 1,1),(4.09,4.60,4.60,5.01 ; 0.7,0.7))$ \\
Poor & $\mathrm{H}=((4.75,6.17,6.92,7.98 ; 1,1),(5.96,6.47,6.47,6.87 ; 0.58,0.58))$ \\
Very Poor & $\mathrm{VH}=((6.75,7.92,8.92,10 ; 1,1),(7.85,8.42,8.41,8.97 ; 0.53,0.53))$ \\
Inferior & $\mathrm{EH}=((8.68,9.91,10,10 ; 1,1),(9.61,9.97,10,10 ; 1,1))$ \\
\hline
\end{tabular}

Table 4. Linguistic terms and their corresponding FOUs for the evaluation of each basic event.

\begin{tabular}{ll}
\hline Linguistic terms & \multicolumn{1}{c}{ FOUs } \\
\hline Extremely Low & $\mathrm{EL}=((0,0,0.59,1.81 ; 1,1),(0,0,0.09,1.16 ; 1,1))$ \\
Very Low & $\mathrm{VL}=((0.18,1,1.50,2.80 ; 1,1),(0.79,1.25,1.25,1.90 ; 0.65,0.65))$ \\
Low & $\mathrm{L}=((0.83,1.70,2.50,3.66 ; 1,1),(1.54,2.04,2.04,2.45 ; 0.56,0.56))$ \\
Slightly Low & $\mathrm{SL}=((1.58,3.00,4.00,5.41 ; 1,1),(2.58,3.5,3.50,4.41 ; 0.65,0.65))$ \\
Medium & $\mathrm{M}=((3.33,4.50,5.25,6.66 ; 1,1),(4.54,4.95,4.95,5.45 ; 0.58,0.58))$ \\
Slightly High & $\mathrm{SH}=((4.33,5.75,6.75,8.16 ; 1,1),(5.33,6.25,6.25,7.16 ; 0.65,0.65))$ \\
High & $\mathrm{H}=((6.10,7.25,8.10,9.01 ; 1,1),(7.53,7.89,7.89,8.31 ; 0.64,0.64))$ \\
Very High & $\mathrm{VH}=((7.15,8.48,9.32,10 ; 1,1),(8.25,8.81,8.81,8.97 ; 0.53,0.53))$ \\
Extremely High & $\mathrm{EH}=((8.03,9.41,10,10 ; 1,1),(8.94,9.92,10,10 ; 1,1))$ \\
\hline
\end{tabular}




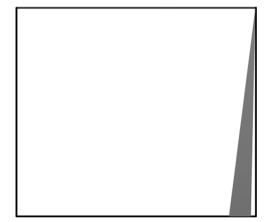

Expert 1

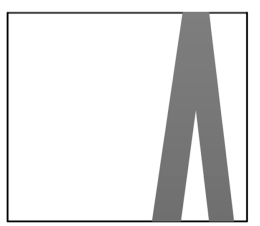

Expert 5

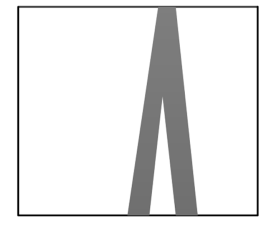

Expert 10
Figure 7. MFs of the WAs of Experts 1, 5, and 10.

MF of Expert 1 (the left picture of Figure 7 ) shows that he has satisfactory expertise and experience in the construction project.

On the other hand, the judgments of experts about the risk of each basic event are reflected in Table 7 . As can be seen in this table, nearly all experts (except Expert 9) have considered that basic event 19 is the most significant factor of project failure, and they considered further risk for this basic event. This issue presents that there is no suitable planning for allocation of financial resources. Thus, the project will stop and failure occurs.

Table 5. Attributed scores to each expert based on his/hers knowledge and experiment.

\begin{tabular}{cccccccc}
\hline \multirow{2}{*}{ Experts } & \multicolumn{7}{c}{ Weights } \\
\cline { 2 - 8 } & EL & VL & L & M & H & VH & EH \\
\hline 1 & 0 & 0 & 0 & 0 & 0 & 0 & 3 \\
2 & 0 & 0 & 0 & 0 & 0 & 2 & 1 \\
3 & 0 & 0 & 0 & 0 & 1 & 1 & 1 \\
4 & 0 & 0 & 0 & 0 & 0 & 1 & 2 \\
5 & 0 & 0 & 0 & 0 & 1 & 2 & 0 \\
6 & 0 & 0 & 0 & 0 & 2 & 1 & 0 \\
7 & 0 & 0 & 0 & 0 & 1 & 0 & 2 \\
8 & 0 & 0 & 0 & 0 & 0 & 3 & 0 \\
9 & 0 & 0 & 0 & 0 & 0 & 3 & 0 \\
10 & 0 & 0 & 0 & 0 & 3 & 0 & 0 \\
\hline
\end{tabular}

\section{Results and discussion}

Established on the stated descriptions of Step 3, the risk of each basic event is calculated. Then, the average centroid ranking method (Eq. (19)) is used to obtain the centroid of all risks. The results are revealed in Table 8 .

The most important factors have the bigger centroid. MFs associated with the top ten most important factors of failure are shown in Figure 8. As can be

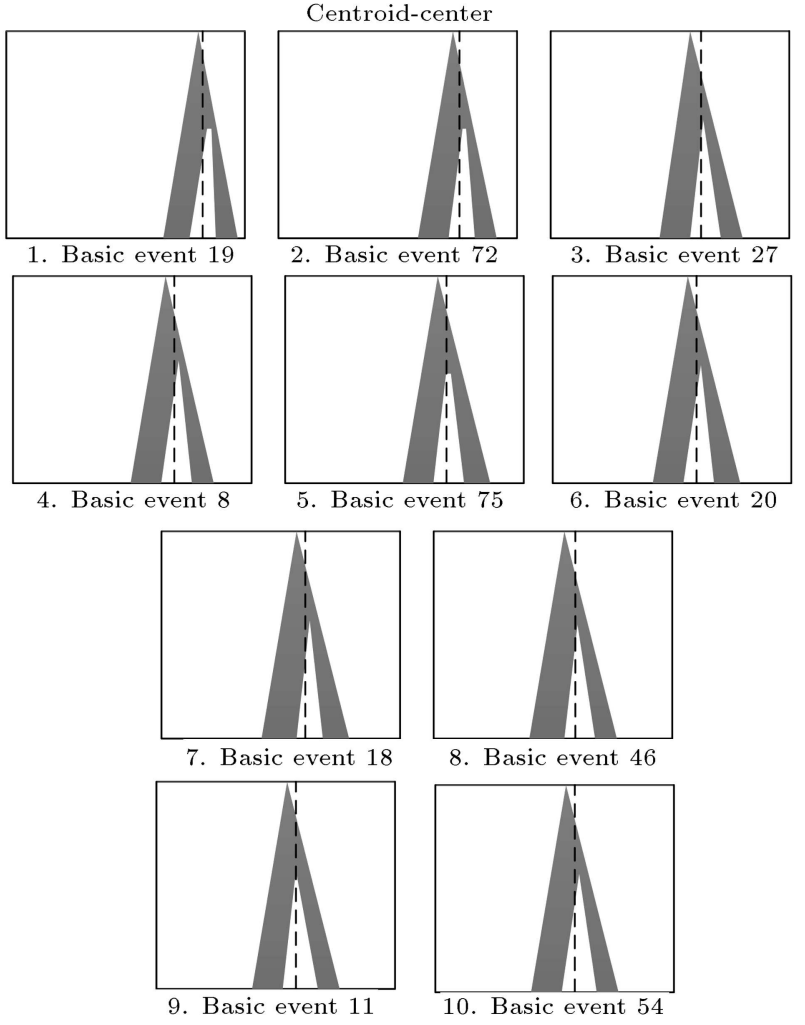

Figure 8. Overall risks of the top ten causes of projects failure.

Table 6. FOUs result for WAs of experts.

\begin{tabular}{ll}
\hline \multirow{2}{*}{ Experts } & \multicolumn{1}{c}{ Final IT2FS of weights } \\
\hline 1 & $\left(\left(a_{i 1}^{U}, a_{i 2}^{U}, a_{i 3}^{U}, a_{i 4}^{U} ; H_{i 1}^{U}, H_{i 2}^{U}\right),\left(a_{i 1}^{L}, a_{i 2}^{L}, a_{i 3}^{L}, a_{i 4}^{L} ; H_{i 1}^{L}, H_{i 2}^{L}\right)\right)$ \\
2 & $(8.68,9.91,10.00,10.00 ; 1.00,1.00),(9.61,9.970,10.00,10.00 ; 1.00,1.00)$ \\
3 & $(7.39,8.58,9.28,10.00 ; 1.00,1.00),(8.44,8.94,8.94,9.31 ; 0.53,0.53)$ \\
4 & $(6.73,8.00,8.61,9.33 ; 1.00,1.00),(7.81,8.29,8.29,8.61 ; 0.53,0.53)$ \\
5 & $(8.04,9.25,9.64,10.00 ; 1.00,1.00),(9.02,9.45,9.47,9.66 ; 0.58,0.58)$ \\
6 & $(6.08,7.34,8.25,9.33, ; 1.00,1.00),(7.22,7.77,7.76,8.27 ; 0.53,0.53)$ \\
7 & $(5.42,6.75,7.59,8.65 ; 1.00,1.00),(6.59,7.12,7.12,7.57 ; 0.58,0.58)$ \\
8 & $(7.37,8.66,8.97,9.33 ; 1.00,1.00),(8.39,8.80,8.82,8.96 ; 0.58,0.58)$ \\
9 & $(6.75,7.92,8.92,10 ; 1.00,1.00),(7.85,8.42,8.41,8.97 ; 0.64,0.64)$ \\
10 & $(4.75,6.17,6.92,7.98 ; 1.00,1.00),(5.96,6.47,6.47,6.87 ; 0.64,0.64)$ \\
\hline
\end{tabular}


Table 7. Linguist terms given by experts to each basic events.

\begin{tabular}{|c|c|c|c|c|c|c|c|c|c|c|}
\hline $\begin{array}{l}\text { Basic } \\
\text { events }\end{array}$ & Expert 1 & Expert 2 & Expert 3 & Expert 4 & Expert 5 & Expert 6 & Expert 7 & Expert 8 & Expert 9 & Expert 10 \\
\hline 1 & $\mathrm{M}$ & SL & $\mathrm{L}$ & $\mathrm{VL}$ & $\mathrm{L}$ & SL & SL & $\mathrm{L}$ & $\mathrm{VL}$ & $\mathrm{M}$ \\
\hline 2 & VL & $\mathrm{SL}$ & VL & $\mathrm{VL}$ & SL & $\mathrm{VL}$ & VL & SL & M & $\mathrm{H}$ \\
\hline 3 & VL & $\mathrm{H}$ & $\mathrm{H}$ & SL & VL & SL & VL & $\mathrm{L}$ & $\mathrm{M}$ & $\mathrm{M}$ \\
\hline 4 & SL & SH & M & SL & SH & M & $\mathrm{SL}$ & $\mathrm{L}$ & VL & VL \\
\hline 5 & $\mathrm{~L}$ & M & SL & SL & $\mathrm{L}$ & M & M & M & SL & $\mathrm{L}$ \\
\hline 6 & VH & M & $\mathrm{L}$ & M & VL & $\mathrm{H}$ & $\mathrm{VL}$ & $\mathrm{L}$ & SL & $\mathrm{L}$ \\
\hline 7 & VL & VL & VL & VL & SL & M & SL & M & VL & VL \\
\hline 8 & $\mathrm{H}$ & SH & $\mathrm{H}$ & $\mathrm{H}$ & SH & $\mathrm{H}$ & M & SH & $\mathrm{H}$ & M \\
\hline 9 & SH & M & SL & SL & SH & M & SL & M & M & M \\
\hline 10 & SH & $\mathrm{M}$ & $\mathrm{M}$ & $\mathrm{M}$ & SH & $\mathrm{M}$ & $\mathrm{M}$ & $\mathrm{H}$ & SH & SH \\
\hline 11 & SH & $\mathrm{M}$ & $\mathrm{H}$ & $\mathrm{M}$ & SH & $\mathrm{M}$ & SH & SH & $\mathrm{H}$ & SL \\
\hline 12 & VL & $\mathrm{L}$ & VL & $\mathrm{VL}$ & $\mathrm{L}$ & $\mathrm{L}$ & $\mathrm{VL}$ & EL & $\mathrm{L}$ & $\mathrm{L}$ \\
\hline 13 & VL & $\mathrm{M}$ & VL & EL & $\mathrm{M}$ & VL & EL & $\mathrm{M}$ & VL & $\mathrm{M}$ \\
\hline 14 & $\mathrm{~L}$ & $\mathrm{~L}$ & VL & EL & SL & EL & $\mathrm{L}$ & $\mathrm{L}$ & VL & $\mathrm{SL}$ \\
\hline 15 & $\mathrm{SH}$ & $\mathrm{M}$ & $\mathrm{L}$ & $\mathrm{VL}$ & SL & $\mathrm{M}$ & $\mathrm{SL}$ & VL & $\mathrm{L}$ & SL \\
\hline 16 & $\mathrm{H}$ & $\mathrm{SH}$ & $\mathrm{SL}$ & $\mathrm{M}$ & $\mathrm{H}$ & $\mathrm{SH}$ & $\mathrm{H}$ & $\mathrm{M}$ & $\mathrm{SL}$ & SL \\
\hline 17 & $\mathrm{M}$ & $\mathrm{VL}$ & $\mathrm{L}$ & $\mathrm{SL}$ & SL & $\mathrm{VL}$ & $\mathrm{L}$ & $\mathrm{L}$ & $\mathrm{SL}$ & VL \\
\hline 18 & $\mathrm{H}$ & $\mathrm{M}$ & $\mathrm{M}$ & $\mathrm{M}$ & $\mathrm{SH}$ & $\mathrm{SH}$ & $\mathrm{H}$ & $\mathrm{M}$ & $\mathrm{M}$ & $\mathrm{H}$ \\
\hline 19 & $\mathrm{EH}$ & $\mathrm{EH}$ & VH & $\mathrm{VH}$ & $\mathrm{EH}$ & $\mathrm{SH}$ & $\mathrm{H}$ & $\mathrm{VH}$ & $\mathrm{M}$ & $\mathrm{VH}$ \\
\hline 20 & $\mathrm{H}$ & $\mathrm{SH}$ & $\mathrm{M}$ & $\mathrm{M}$ & $\mathrm{M}$ & $\mathrm{M}$ & SH & $\mathrm{H}$ & $\mathrm{H}$ & $\mathrm{M}$ \\
\hline 21 & SL & $\mathrm{M}$ & $\mathrm{VL}$ & $\mathrm{VL}$ & $\mathrm{M}$ & $\mathrm{M}$ & $\mathrm{M}$ & $\mathrm{L}$ & SL & VL \\
\hline 22 & VL & $\mathrm{L}$ & EL & $\mathrm{VL}$ & $\mathrm{L}$ & EL & EL & $\mathrm{VL}$ & $\mathrm{SL}$ & SL \\
\hline 23 & VL & $\mathrm{L}$ & $\mathrm{VL}$ & SL & SL & $\mathrm{L}$ & SL & VL & $\mathrm{L}$ & VL \\
\hline 24 & $\mathrm{~L}$ & $\mathrm{M}$ & $\mathrm{L}$ & $\mathrm{SL}$ & SL & $\mathrm{SL}$ & $\mathrm{L}$ & $\mathrm{M}$ & $\mathrm{L}$ & $\mathrm{M}$ \\
\hline 25 & $\mathrm{~L}$ & $\mathrm{~L}$ & SL & $\mathrm{VL}$ & $\mathrm{M}$ & $\mathrm{VL}$ & $\mathrm{VL}$ & SL & $\mathrm{L}$ & $\mathrm{M}$ \\
\hline 26 & $\mathrm{SL}$ & SL & $\mathrm{M}$ & $\mathrm{SL}$ & $\mathrm{L}$ & $\mathrm{M}$ & $\mathrm{M}$ & $\mathrm{SL}$ & $\mathrm{SL}$ & $\mathrm{L}$ \\
\hline 27 & $\mathrm{VH}$ & $\mathrm{VH}$ & $\mathrm{H}$ & $\mathrm{M}$ & $\mathrm{SH}$ & $\mathrm{H}$ & $\mathrm{H}$ & $\mathrm{SH}$ & $\mathrm{M}$ & $\mathrm{M}$ \\
\hline 28 & $\mathrm{SL}$ & $\mathrm{SL}$ & $\mathrm{M}$ & $\mathrm{SL}$ & $\mathrm{M}$ & $\mathrm{SL}$ & $\mathrm{L}$ & $\mathrm{SL}$ & $\mathrm{VL}$ & VL \\
\hline 29 & L & $\mathrm{L}$ & SL & VL & SL & $\mathrm{L}$ & $\mathrm{L}$ & VL & SL & $\mathrm{L}$ \\
\hline 30 & M & $\mathrm{H}$ & $\mathrm{H}$ & M & SH & M & M & $\mathrm{L}$ & $\mathrm{H}$ & SL \\
\hline 31 & VL & $\mathrm{L}$ & SL & SL & $\mathrm{M}$ & SL & SL & $\mathrm{L}$ & $\mathrm{L}$ & VL \\
\hline 32 & $\mathrm{M}$ & SL & SL & SL & $\mathrm{L}$ & $\mathrm{M}$ & $\mathrm{M}$ & SL & L & L \\
\hline 33 & SL & SL & M & SL & $\mathrm{L}$ & $\mathrm{M}$ & SL & $\mathrm{M}$ & M & L \\
\hline 34 & VL & VL & VL & SL & SL & VL & VL & $\mathrm{L}$ & SL & SL \\
\hline 35 & SL & SL & M & $\mathrm{M}$ & $\mathrm{L}$ & $\mathrm{L}$ & $\mathrm{M}$ & SL & SL & L \\
\hline 36 & VL & $\mathrm{L}$ & $\mathrm{L}$ & VL & SL & VL & SL & L & VL & L \\
\hline 37 & $\mathrm{~L}$ & $\mathrm{~L}$ & $\mathrm{~L}$ & M & SL & SL & $\mathrm{M}$ & $\mathrm{M}$ & SL & $\mathrm{H}$ \\
\hline 38 & VL & M & SL & VL & $\mathrm{M}$ & SL & SL & L & VL & $\mathrm{M}$ \\
\hline 39 & SL & M & M & M & SL & $\mathrm{L}$ & $\mathrm{L}$ & VL & SL & $\mathrm{M}$ \\
\hline 40 & SH & M & M & M & $\mathrm{H}$ & $\mathrm{H}$ & M & SL & M & $\mathrm{H}$ \\
\hline 41 & $\mathrm{~L}$ & $\mathrm{H}$ & SH & M & SL & $\mathrm{H}$ & $\mathrm{H}$ & SL & $\mathrm{H}$ & L \\
\hline 42 & M & $\mathrm{H}$ & SH & SL & M & SH & M & M & $\mathrm{H}$ & $\mathrm{SH}$ \\
\hline 43 & SL & M & M & SL & M & M & SL & SL & M & M \\
\hline 44 & VL & VL & VL & SL & L & VL & SL & SL & VL & $\mathrm{L}$ \\
\hline 45 & SL & M & SL & VL & $\mathrm{M}$ & L & SL & $\mathrm{M}$ & VL & $\mathrm{L}$ \\
\hline 46 & $\mathrm{H}$ & $\mathrm{H}$ & $\mathrm{M}$ & $\mathrm{L}$ & SL & $\mathrm{M}$ & $\mathrm{H}$ & $\mathrm{H}$ & SH & $\mathrm{H}$ \\
\hline 47 & M & M & SL & VL & L & VL & L & $\mathrm{M}$ & SL & $\mathrm{M}$ \\
\hline 48 & $\mathrm{M}$ & M & SL & VL & $\mathrm{M}$ & VL & SL & $\mathrm{L}$ & $\mathrm{M}$ & SL \\
\hline 49 & VL & $\mathrm{L}$ & VL & VL & VL & $\mathrm{L}$ & SL & $\mathrm{L}$ & VL & $\mathrm{M}$ \\
\hline
\end{tabular}


Table 7. Linguist terms given by experts to each basic events (continued).

\begin{tabular}{|c|c|c|c|c|c|c|c|c|c|c|}
\hline $\begin{array}{c}\text { Basic } \\
\text { events }\end{array}$ & Expert 1 & Expert 2 & Expert 3 & 3 Expert 4 & Expert 5 & Expert 6 & Expert 7 & Expert 8 & Expert 9 & Expert 10 \\
\hline 50 & $\mathrm{M}$ & VL & $\mathrm{L}$ & SL & SL & $\mathrm{M}$ & SL & SL & VL & SL \\
\hline 51 & M & M & $\mathrm{M}$ & M & SL & $\mathrm{L}$ & SL & VL & $\mathrm{L}$ & $\mathrm{M}$ \\
\hline 52 & SL & $\mathrm{L}$ & VL & VL & $\mathrm{VL}$ & $\mathrm{L}$ & $\mathrm{L}$ & SL & SL & $\mathrm{L}$ \\
\hline 53 & SL & $\mathrm{L}$ & SL & VL & $\mathrm{VL}$ & SL & $\mathrm{L}$ & VL & M & $\mathrm{VL}$ \\
\hline 54 & SH & $\mathrm{H}$ & SL & $\mathrm{M}$ & $\mathrm{H}$ & $\mathrm{H}$ & $\mathrm{H}$ & $\mathrm{H}$ & VL & $\mathrm{M}$ \\
\hline 55 & $\mathrm{M}$ & $\mathrm{M}$ & SL & SL & SL & M & M & SL & SL & $\mathrm{L}$ \\
\hline 56 & $\mathrm{H}$ & SL & M & SL & M & M & M & SL & SL & $\mathrm{L}$ \\
\hline 57 & $\mathrm{~L}$ & M & VL & $\mathrm{L}$ & $\mathrm{L}$ & $\mathrm{L}$ & VL & SL & M & M \\
\hline 58 & SH & M & M & M & SH & M & M & VL & $\mathrm{L}$ & SL \\
\hline 59 & SL & $\mathrm{M}$ & $\mathrm{L}$ & VL & M & M & M & SL & $\mathrm{L}$ & $\mathrm{VL}$ \\
\hline 60 & SL & M & $\mathrm{M}$ & M & M & M & M & SL & SL & $\mathrm{L}$ \\
\hline 61 & SL & SL & SH & M & SL & $\mathrm{H}$ & M & $\mathrm{SH}$ & M & M \\
\hline 62 & $\mathrm{~L}$ & $\mathrm{M}$ & $\mathrm{L}$ & VL & $\mathrm{L}$ & $\mathrm{L}$ & $\mathrm{L}$ & M & SL & $\mathrm{L}$ \\
\hline 63 & $\mathrm{~L}$ & $\mathrm{M}$ & $\mathrm{L}$ & VL & SL & M & M & $\mathrm{L}$ & SL & $\mathrm{VL}$ \\
\hline 64 & M & M & M & SL & $\mathrm{L}$ & M & SL & $\mathrm{L}$ & SL & $\mathrm{L}$ \\
\hline 65 & $\mathrm{~L}$ & VL & EL & VL & EL & EL & $\mathrm{L}$ & EL & $\mathrm{L}$ & M \\
\hline 66 & $\mathrm{VL}$ & $\mathrm{L}$ & VL & VL & SL & $\mathrm{L}$ & $\mathrm{L}$ & SL & $\mathrm{L}$ & SL \\
\hline 67 & VL & $\mathrm{M}$ & $\mathrm{M}$ & SL & SL & $\mathrm{M}$ & $\mathrm{M}$ & SL & $\mathrm{L}$ & $\mathrm{M}$ \\
\hline 68 & $\mathrm{M}$ & $\mathrm{H}$ & $\mathrm{M}$ & $\mathrm{M}$ & $\mathrm{SH}$ & $\mathrm{M}$ & $\mathrm{M}$ & $\mathrm{H}$ & $\mathrm{SH}$ & $\mathrm{SH}$ \\
\hline 69 & VL & $\mathrm{L}$ & $\mathrm{VL}$ & VL & SL & VL & VL & $\mathrm{L}$ & SL & $\mathrm{L}$ \\
\hline 70 & $\mathrm{M}$ & SL & SL & SL & $\mathrm{L}$ & $\mathrm{M}$ & $\mathrm{M}$ & SL & $\mathrm{M}$ & $\mathrm{VL}$ \\
\hline 71 & $\mathrm{M}$ & VL & $\mathrm{L}$ & VL & VL & $\mathrm{M}$ & $\mathrm{M}$ & $\mathrm{VL}$ & $\mathrm{L}$ & SL \\
\hline 72 & $\mathrm{VH}$ & VH & $\mathrm{EH}$ & $\mathrm{VH}$ & $\mathrm{VH}$ & $\mathrm{H}$ & $\mathrm{M}$ & $\mathrm{M}$ & VH & SH \\
\hline 73 & VL & VL & $\mathrm{L}$ & $\mathrm{M}$ & $\mathrm{M}$ & $\mathrm{M}$ & SL & $\mathrm{L}$ & SL & SL \\
\hline 74 & SL & VL & $\mathrm{L}$ & VL & $\mathrm{L}$ & $\mathrm{L}$ & SL & SL & $\mathrm{L}$ & $\mathrm{VL}$ \\
\hline 75 & SH & $\mathrm{H}$ & SH & M & $\mathrm{H}$ & SH & $\mathrm{H}$ & $\mathrm{M}$ & M & $\mathrm{H}$ \\
\hline
\end{tabular}

seen in this figure, the acquired results exemplify more information about the uncertainties of linguistic words. Hence, by making use of the additional information provided by IT2FSs from the beginning of the calculations up to the time when final results are obtained, our proposed procedure benefits decision-makers in making more reliable choices.

The top ten most important causes of failure are discussed as follows: Basic events 19, 8, 18, and 11 are related to financial problems. It is clear that this problem leads to delay in work progress, because there will be insufficient cash flow to support construction expenditures. This issue increases financial problems of the contractor. In particular, in Iran, financial problems of contractors are more than other countries, since most Iranian contractors are small and independent, and they have limited access to credit facilities.

Basic events 72 and 75 are about the contractor selection process. We know that every construction project comprises initial planning, design, and construction stages. In terms of expenditure, the construction stage is the most outstanding one, because about 90 percent of total project funding is expended throughout the construction stage. Consequently, choosing a suitable contractor definitely helps achieve overall success and good performance. In Iran and many other countries, contracts are normally awarded to the lowest bid price. It is understandable that the objectives, such as construction time and final quality of a project, are likely to be overlooked with the simple selection of cost minimization, while these objectives are generally more desirable and appropriate. Thus, the lowest bidder is not always the most economic choice, and so the risk of poor performance rises with it. With the accurate selection of pre-qualified contractors, the above-mentioned problem will be significantly reduced. In the prequalification method, first, the pool of contractors is examined, and then the short list of contractors is requested to contribute to the bidding process. If this process is conducted properly, 
Table 8. The obtained centroid for overall risk of each basic event.

\begin{tabular}{cccccc}
\hline Basic event & Centroid & Basic event & Centroid & Basic event & Centroid \\
\hline 1 & 2.9 & 26 & 3.6 & 51 & 3.7 \\
2 & 2.8 & 27 & 6.3 & 52 & 2.3 \\
3 & 3.8 & 28 & 3.2 & 53 & 2.5 \\
4 & 3.7 & 29 & 2.3 & 54 & 5.9 \\
5 & 3.6 & 30 & 5.7 & 55 & 3.9 \\
6 & 3.9 & 31 & 2.8 & 56 & 4.4 \\
7 & 2.4 & 32 & 3.5 & 57 & 2.9 \\
8 & 6.7 & 33 & 3.8 & 58 & 4.4 \\
9 & 4.7 & 34 & 2.2 & 59 & 3.3 \\
10 & 5.7 & 35 & 3.6 & 60 & 4.2 \\
11 & 5.9 & 36 & 2.0 & 61 & 4.9 \\
12 & 1.6 & 37 & 3.8 & 62 & 2.7 \\
13 & 2.5 & 38 & 3.0 & 63 & 3.1 \\
14 & 1.9 & 39 & 3.6 & 64 & 3.7 \\
15 & 3.3 & 40 & 5.6 & 65 & 1.6 \\
16 & 5.6 & 41 & 5.3 & 66 & 2.2 \\
17 & 2.6 & 42 & 5.7 & 67 & 3.7 \\
18 & 6.0 & 43 & 4.3 & 68 & 5.7 \\
19 & 8.1 & 44 & 2.1 & 69 & 2.0 \\
20 & 6.1 & 45 & 3.2 & 70 & 3.8 \\
21 & 3.3 & 46 & 6.0 & 71 & 2.8 \\
22 & 1.6 & 47 & 3.4 & 72 & 7.6 \\
23 & 2.2 & 48 & 3.5 & 73 & 3.1 \\
24 & 3.3 & 49 & 2.1 & 74 & 2.2 \\
25 & 2.6 & 50 & 3.2 & 75 & 6.8 \\
\hline
\end{tabular}

the selected contractor likely completes the project satisfactorily.

Basic event 27, as the third important factor of failure, is justified as follows.

Changes and/or additional works stem from uncertainties, faults, and discrepancies in specifications and drawings. The order of changes has remarkable effect on the financial performance of a construction project. These change orders can be reduced if the following conditions are considered:

(a) Carrying out precise preliminary studies of the project by consultants;

(b) Allocation of adequate time for preliminary studies;

(c) Clear and continuous discussion about the objectives of a project between the consultant and client;

(d) Establishment of correct descriptions of client requirements by consultants.

\section{Case study}

In order to validate the results of the current study, in this section, a real case study causing failure is investigated.

The project in question is the construction of the second lane of Miandoab-Kermanshah highway that is located in three different provinces: West Azarbayjan,
Kurdestan, and Kermanshah. With a length of $440 \mathrm{~km}$, it was divided into eleven parts, such that each part was awarded to one independent contractor. Furthermore, it has a width of 7.30 meters. The main objective of this project is to increase transportation capacity. Safety improvement and reduction of accidents are the other aims of this project. The longest part of this project belongs to part 11 with allotted time of 30 months in the related contract. Since construction of different parts is independent, the construction of all parts must be completed in 30 months. Conversely, after 12 years, the construction of this project is yet to reach completion, and construction cost has reached five times the estimated sum, such that the project has lost its economic justification.

In order to survey the causes of failure, eleven project managers of the case study were asked to help us find the key factors of failure. First, through FTA and interview with the project managers, forty-two basic events were identified. Twenty-one identified basic events are basic events $2,5,6,8,11,15,19$, $20,24,27,31,35,37,42,45,50,52,53,55,56$, and 57 of Figure 2. Other identified basic events are listed in Table 9. As it can be seen, the risks of rows 1 and 4 in this table are only related to road construction projects and other risks can occur in each construction project.

To rank the basic events, the project managers were asked to respond to the risk of each basic event. 
Table 9. Some of the basic events related to the case study failure.

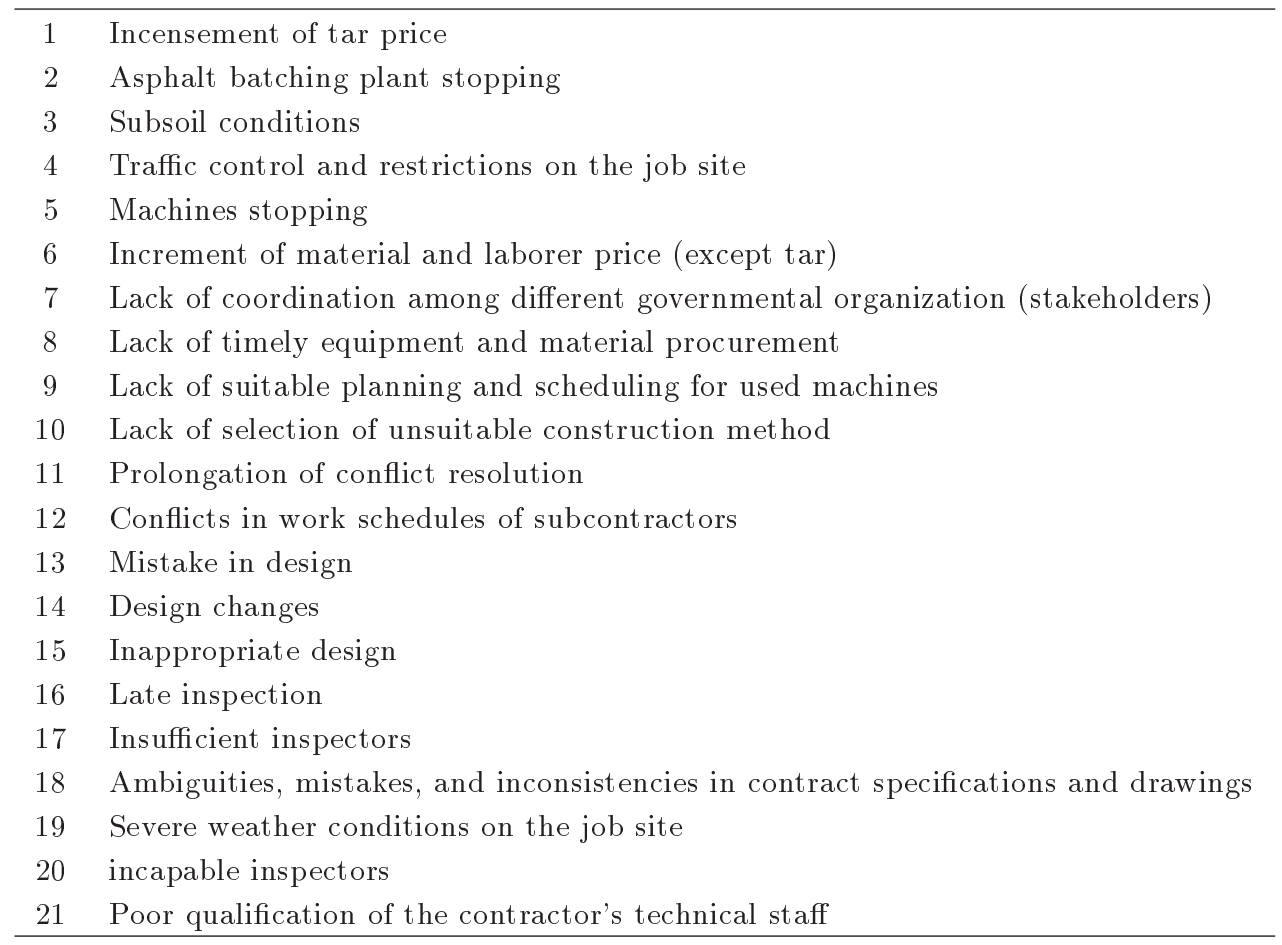

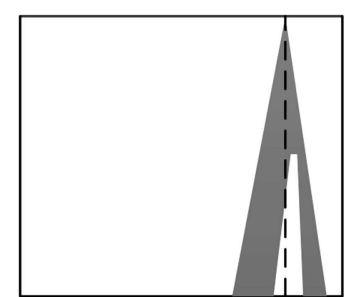

--- Centroid-center $=8.2$

1. Lack of timely financial allocation

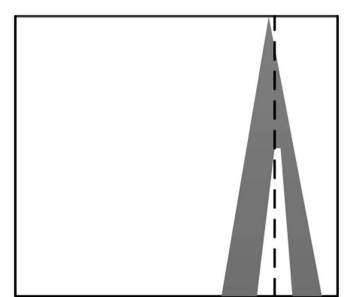

--- Centroid-center $=8.1$

2. Payement delays to the contractor

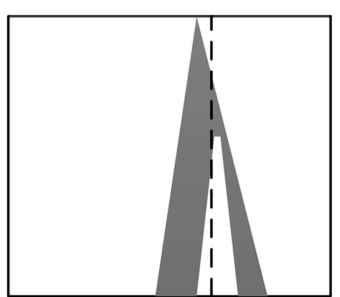

--- Centroid-center $=6.3$

3. Changes and/or additional works

Figure 9. MFs results of top three key factors of the project failure (related to case study).

Then, the proposed methodology outlined in Section 3 was used to identify key factors of case studies' project failure. The MFs results of top three key factors of the project failure are presented in Figure 9 . As can be seen, the case study also confirms that financial problems are the most important factors of construction project failure. In the case study, these issues caused the project to stop several times.

Also, the Research Center of the Islamic Republic of Iran's parliament has been investigating the causes of this failure. Its reports present that in the tender stage, none of the contractors was qualified and all contracts were awarded to the lowest bids. On the other hand, in the construction stage, due to payment delays to the contractor, in most cases, the project has stopped. Likewise, path changes in some parts of the project have led to a continuous design stage. As can be seen, this actual case study validates the obtained results.

\section{Conclusion}

In most countries, public sector projects absorb a high percentage of the capital asset investment from the state budget. Reports indicate that failure is the predominant fate of most of them. Consequently, many researchers have attempted to investigate the key factors behind project failure, and for this purpose, most of them have used crisp value conceptions. Nonetheless, due to the complexity in construction projects, using this tool is inappropriate and results in unreliable outcomes. When we are confronted with uncertainties, undeniably, one of the best methods is employing fuzzy concepts. We recognize that FT1 is only applicable in one-person decision-making problems. In multi-person decision making, since experts have no unified agreement on $\mathrm{MFs}$, then applying FT2Ss is more justifiable. Consequently, in the current 
study, the root factors of project failure were initially identified through FTA. Then, we ranked them using the T2FSs approach. In the last section, a case study was provided to validate our results.

Future studies could focus on exploring inadequacies of construction bidding procedures of public sector projects. Furthermore, proposing a decisionmaking model for contractor prequalification using T2FSs could be another topic for future studies.

\section{Nomenclature}

FTA Fault Tree Analysis

LWA Linguistic Weighted Average

IT2FSs Interval Type-2 Fuzzy Sets

KTX Korea Train eXpress

RII Relative Importance Index

FT1 Fuzzy Type-1

FT1Ss Fuzzy Type-1 Sets

FT2 Fuzzy Type-2

$\square$ AND gate

OR gate

WA Weighted Average

$\tilde{W}_{j} \quad$ Weighted average of expert $j$

$w_{j}^{q} \quad$ Linguistic term assigned to each expert $j$ in criterion $q$

$N \quad$ The sample size

$N \quad$ The population size

$Z \quad$ Standard normal quantile

$A \quad$ The confidence level

$P \quad$ The estimated proportion of an attribute that is present in the population

$\varepsilon \quad$ The level of precision

$\tilde{R}_{i} \quad$ The overall risk of basic event $i$

$\tilde{X}_{i j} \quad$ The response of expert $j$ about the risk of basic event $i$

MFs Membership Functions

MF Membership Function

$\tilde{A} \quad$ A type-1 fuzzy set

$\mu_{\tilde{A}}(x) \quad$ MF of $\tilde{A}$

$c(A) \quad$ Centroid of a T1FS

$\tilde{\tilde{A}} \quad$ A general type-2 fuzzy set

$\mu_{\tilde{\tilde{A}}}(x, u) \quad$ Type-2 MFs

FOU Footprint Of Uncertainty

UMF Upper Membership Function

LMF Lower Membership Function
$c(\tilde{A}) \quad$ Centroid of a T1FS

$c(\operatorname{UML}(\tilde{A}))$ Centroid of UMF

$c(\operatorname{LMF}(\tilde{A})) \quad$ Centroid of LMF

EIA Enhanced Interval Approach

WAs Weighted Averages

\section{References}

1. Shahhosseini, V. and Sebt, M.H. "Competency-based selection and assignment of human resources to construction projects", Scientia Iranica, 18(2), pp. 163180 (2011).

2. http://www.entekhab.ir/fa/news/257038.

3. Han, S.H., Yun, S., Kim, H., Kwak, Y.H., Park, H.K. and Lee, S.H. "Analyzing schedule delay of mega project: lessons learned from Korea train express", IEEE Transactions on Engineering Management, 56, pp. 243-256 (2009).

4. Abdul-Rahman, H., Takim, R. and Min, W.S. "Financial-related causes contributing to project delays", Journal of Retail \& Leisure Property, 8, pp. 225238 (2009).

5. Yang, J.B. and Wei, P.R. "Causes of delay in the planning and design phases for construction projects", J. Architect. Eng., 16(2), pp. 80-83 (2010).

6. Soliman, E.M. "Delay causes in Kuwait construction projects", in: AICSGE7, Proceedings of Seventh Alexandria International Conference on Structural and Geotechnical Engineering, pp. 57-67 (2010).

7. Hasseb, M., Bibi, A., Dyian, M. and Rabbani, W. "Problems of projects and effects of delays in the construction industry of Pakistan", Austr. J. Bus. Manage. Res., 1(5), pp. 41-50 (2011).

8. Doloi, H., Sawhney, A., Iyer, K.C. and Rentala, S. "Analysing factors affecting delays in Indian construction projects", International Journal of Project Management, 30, pp. 479-489 (2012).

9. Ezeldin, A. and Abdel-Ghany, M. "Causes of construction delays for engineering projects: an Egyptian perspective", AEI, pp. 54-63 (2013).

10. Rahsid, Y., Haq, S. and Aslam, M. "Causes of delay in construction projects of Punjab-Pakistan: an empirical study", J. Basic Appl. Sci. Res., 3(10), pp. 87-96 (2013).

11. Marzouk, M.M. and El-Rasas, T.I. "Analyzing delay causes in Egyptian construction projects", Journal of Advanced Research, 5(1), pp. 49-55 (2014).

12. Ruqaishi, M. and Bashir, H. "Causes of delay in construction projects in the oil and gas industry in the gulf cooperation council countries: a case study", J. Manage. Eng., 31(3), pp. 5014-5017 (2013). 
13. Remon, F.A. and Abdel-Hakam, A.A. "Exploring delay causes of road construction projects in Egypt", Alexandria Engineering Journal, 55(2), pp. 1515-1539 (2016).

14. Gunduz, M., Nielsen, Y. and Ozdemir, M. "Quantification of delay factors using Relative Importance Index (RII) method for construction projects in Turkey", $J$. Manage. Eng., 29(2), pp. 133-139 (2013).

15. Ferdous, R. "Methodology for computer aided fuzzy fault tree analysis", Thesis presented to the Memorial University of Newfoundland in Partial Fulfillment of the Requirement for Master Degree (2006).

16. Johnson, P.A. "Fault tree analysis of bridge failure due to scour and channel instability", J. Infrastruct. Syst., $A S C E$, 5(1), pp. 35-41 (1999).

17. Wu, D. and Mendel, J.M. "A comparative study of ranking methods, similarity measures and uncertainty measures for interval type-2 fuzzy sets", Information Sciences, $179(8)$, pp. 1169-1192 (2009).

18. Cochran, W.G., Sampling Techniques, 3rd Ed., New York: John Wiley \& Sons (1977).

19. Gilan, S.S., Sebt, M.H. and Shahhosseini, V. "Computing with words for hierarchical competency based selection of personnel in construction companies", Applied Soft Computing, 12, pp. 860-871 (2012).

20. Nasirzadeha, F., Rouhparvarb, M., Mazandarani Zadehc, H. and Rezaie, M. "Integrating system dynamics and fuzzy bargaining for quantitative risk allocation in construction projects", Scientia Iranica A, 22(3), pp. 668-678 (2015).

21. Levy, P.S. and Lemeshow, S., Sampling of Populations: Methods And Applications, 3rd Ed., New York, WileyInterscience (1999).

22. Mendel, J.M. "Fuzzy sets for words: a new beginning", In: Proceeding of IEEE International Conference on Fuzzy Systems, St. Louis, MO, pp. 37-42 (2003).

23. Mendel, J.M., John, R.I. and Liu, F.L. "Interval type-2 fuzzy logical systems made simple", 5 IEEE Transactions on Fuzzy Systems, 14(6), pp. 808-821 (2006).

24. Chen, S.M. and Lee, L.W. "Fuzzy multiple criteria hierarchical group decision-making based on interval type-2 fuzzy sets", IEEE Transactions on Systems,
Man and Cybernetics, Part A: Systems and Humans, 40(5), pp. 1120-1128 (2012).

\section{Biographies}

Vahid Shahhosseini is an Assistant Professor in the Department of Civil and Environmental Engineering at Amirkabir University of Technology. He received his $\mathrm{PhD}$ in Construction Engineering and Management from Amirkabir University of Technology, Iran. He teaches Project Management, Construction Equipment Management, and Project Planning and Control. His research interests include construction management, project management, resource allocation, optimization, computer simulations, expert systems, and fuzzy logic and adaptive intelligent systems. He has published several research papers in national and international journals and conference proceedings.

Mohammad Reza Afshar obtained his BS degree in Civil Engineering from Zanjan University, Iran. He received his MS degree in Civil Engineering, Construction Engineering and Management from Amirkabir University of Technology. He is also top one graduated student in this course. His research interests are related to construction management, risk analysis, project scheduling problem, optimization and fuzzy logic. He has published 12 research papers in international and national conference proceedings and national journals.

Omid Amiri obtained his BS degree in Civil Engineering from Shahrood University, Iran. He received his MS degree in Civil Engineering, Construction Engineering and Management from Amirkabir University of Technology. Every year, He holds different seminars about the tender stage, price list, and causes of construction project failure in different areas of Iran. His research interests are related to risk analysis, project management, and construction contractor prequalification. He has published 98 research papers in international and national conference proceedings, national journals, and several books. 